https://dx.doi.org/10.4314/ijs.v21i2.6

Ife Journal of Science vol. 21, no. 2 (2019)

\title{
EMERGENCE OF METALLO- $\beta$-LACTAMASE PRODUCING GRAM-NEGATIVE BACTERIA IN A HOSPITAL WITH NO HISTORY OF CARBAPENEM USAGE IN NORTHWEST NIGERIA
}

\author{
Olowo-okere, A. ${ }^{1 \%}$, Abdullahi, M. A. ${ }^{1}$, Ladidi, B. K. ${ }^{1}$, Suleiman, S. ${ }^{1}$, Tanko, N. ${ }^{1}$, \\ Ungokore, H. Y. ${ }^{1}$, Aliyu, A. ${ }^{2}$ \\ 'Department of Pharmaceutics and Pharmaceutical Microbiology, Usmanu Danfodiyo University Sokoto, Nigeria. \\ ${ }^{2}$ Department of Pharmaceutical Microbiology and Biotechnology, University of Ilorin, Nigeria. \\ *Corresponding author's e-mail: olowookere.ahmed@udusok.edu.ng, Tel: +234-703-110-2745
}

(Received: $5^{\text {th }}$ January, 2019; Accepted: $12^{\text {th }}$ May, 2019)

\section{ABSTRACT}

Carbapenems are among the antibiotics of last resort against infections caused by antibiotic resistant bacteria. However, resistance to this important class of antibiotic is on the increase due to expression of metallo-betalactamases (MBLs). This study investigated the occurrence of MBL-producing bacteria in a healthcare facility in Sokoto, Nigeria. Swabs were collected from the rectum $(n=29)$ and bed linens $(n=27)$ of patients within the surgical wards of the hospital between March and August, 2018 and processed using Centers for Disease Control and Prevention (CDC) broth enrichment method for isolation of carbapenem resistant Gram-negative bacteria (CR-GNB). In addition, 110 bacteria isolated from clinical specimens submitted to microbiology laboratory of the hospital were collected and tested for susceptibility to antibiotics using the disc diffusion method. The carbapenem resistant isolates were further evaluated for MBL-production using the combined disc method. Overall, 31(28.2\%) of the Gram-negative bacterial isolates were carbapenem resistant. The most predominant isolated bacterium in this study was E. coli $(18 ; 36 \%)$. The isolates were highly resistant to cephalosporins $(74 \%)$ and fluoroquinolones $(52.7 \%)$ while remaining moderately susceptible to gentamicin $(38.8 \%)$ and amoxicillin-clavulanate $(45.7 \%)$. Majority of the CR-GNB were extensively drug resistant (19; $38 \%)$ and pan drug resistant (10; 20\%). The MBL-production test revealed that $19(38.0 \%)$ of the CR-GNB were MBL-positive. The study revealed a high prevalence of MBL-producing CR-GNB in a hospital with no history of its use. This report documents for the first time the independent emergence of such resistance in our hospital. Implementation of adequate antibiotic stewardship program is therefore imperative so as to contain this emerging threat.

Keywords: Carbapenem Resistant Bacteria, Metallo- $\beta$-lactamase, Carbapenemase, MDR.

\section{INTRODUCTION}

Carbapenem is a broad-spectrum beta-lactam $(\beta$ lactam) antibiotic, developed as one of the last resort antibiotics for treatment of serious and lifethreatening infections caused by multitude of multidrug resistant (MDR) Gram-negative bacterial infections, including extended spectrum$\beta$-lactamase (ESBL)-producing Gram-negative bacteria (El-gamal et al., 2017; Hsu et al., 2017). The carbapenems were introduced in the late 1980s in response to emergence of ESBLproducing Gram-negative bacteria (Iovleva and Doi, 2017). This was soon overwhelmed by the resilience of bacteria. The plasmid borne genes which encoded Gram-negative $\beta$-lactamase mutated to evolve into more efficient mutants, leading to emergence of first carbapenem resistant Gram-negative bacteria (CR-GNB) in Japan in the early 1990s (Iovleva and Doi, 2017).
Since then, bacteria resistant to carbapenem has emerged and spread in the healthcare settings worldwide (Dortet et al., 2014; Duin and Doi, 2017; Logan and Weinstein, 2017). This constitutes immediate threat to public health with attendant morbidity and mortality and thus requiring urgent and aggressive action (CDC, 2013). In the United States, CR-GNB causes approximately 9300 infections per year and up to half of all CR-GNB bloodstream infections result in death (CDC, 2013). A higher likelihood of death (more than $40 \%$ deaths) has been observed in patients with carbapenem-resistant infections compared with patients infected with carbapenem susceptible organisms (Falagas et al., 2014; Xu et al., 2017). Moreover, longer duration of hospital stays and consequently increased healthcare cost is associated with CR-GNB infections (Magiorakos etal., 2017). 
This resistance has been attributed to a number or combination of diverse mechanisms. These include the production of carbapenemase enzymes, modification of outer membrane permeability and up-regulation of efflux system (Potter et al., 2016). Most notably among these mechanisms is the production of carbapenemases, which are group of broad spectrum $\beta$-lactamase enzymes with hydrolytic activities against all cephalosporins, carbapenems and penicillins (Potter et al., 2016). The enzymes are functionally divided into those possessing serine group at their active site (Ambler classes A and D) and those possessing divalent metal ion(s) at their active site (Ambler Class B or the metallo$\beta$-lactamase) (Iovleva and Doi, 2017; Walsh, 2005). Metallo-beta-lactamases (MBLs) efficiently hydrolyse carbapenems and other $\beta$-lactams (except monobactams) and are not inhibited by the clinically available $\beta$-lactamase inhibitors (Potter et al., 2016). These enzymes are more commonly detected in Klebsiella spp. and Escherichia coli (Hsu et al., 2017). The rapid global spread of this bacteria and accompanied virulence is facilitated by resident of most carbapenemase genes on ambulatory genetic elements (Potter et al., 2016). This is responsible for clonal transfer among bacteria of the same species and horizontal acquisition among bacteria of different species.

In tandem with global trend, the prevalence of CR-GNB in Nigeria is increasing (Aibinu et al., 2007; Ibrahim et al., 2017). The resistance of clinical isolates to carbapenems has increased by about ten-folds within a decade from $4.1 \%$ in 2007 to $40.3 \%$ in 2017 (Aibinu et al., 2007; Ibrahim et al., 2017). Molecular detection methods have also shown high circulation of carbapenemase genes in many Nigerian hospitals (Ogbolu and Webber, 2014; Mohammed et al., 2015).

Though, emergence of carbapenem resistance has been mostly linked to prior carbapenem exposure, its occurrence among patients with no known medical history of its usage has however been documented in several countries including Nigeria (Mohammed et al., 2015). This is similar to the emergence of colistin resistant bacteria among colistin naive patients (Olaitan et al., 2016).
Because of the threat constituted by these organisms, prompt detection of patients with a CR-GNB infection is necessary not only for patient treatment decision and guiding infection control but also for epidemiological surveillance efforts aimed at limiting its spread (Magiorakos et al., 2017). This study therefore aimed to determine the occurrence of MBL-producing bacteria isolates in a healthcare facility in Sokoto, Nigeria.

\section{MATERIALS AND METHODS Ethical Consideration}

Ethical approval to conduct this research was obtained from the hospital ethics and research committee of the hospital with the reference number, SHS/SUB 133/VOL.1. After adequate briefing of patients or their relatives on the objective of the study, informed consent was obtained from all individuals enrolled in the study.

\section{Study Design and Bacterial Isolates}

This prospective observational study was conducted in a tertiary healthcare facility in Sokoto, Nigeria. Non-duplicate clinical isolates of Gram-negative bacteria isolated from routine clinical specimens brought to the microbiology laboratory of the hospital, were collected between March and August, 2018. Validated questionnaires were also administered to collect information on socio-demographic and clinical characteristics of patients from the patients' medical record.

\section{Sample Collections}

Rectal $(n=29)$ and bed linens $(n=27)$ swabs of both male and female patients of all ages on admission within the surgical wards of the hospital during the study period were collected. The swabs were processed within two hours after collection using the standard microbiological techniques such as culturing, isolation and identification. In addition, 110 bacteria isolated from clinical specimens submitted to microbiology laboratory of the hospital were collected and tested for susceptibility to antibiotics using the disc diffusion method.

\section{Screening, Isolation and Identification of Carbapenem-Resistant Bacteria}

The screening and isolation of CR-GNB was 
done in accordance with the United States Centers for Disease Control and Prevention (CDC) isolation protocol for $\mathrm{CRB}$ as previously described (CDC, 2011). Briefly, swabs were inoculated into $5 \mathrm{ml}$ of sterile trypticase soy broth (TSB) in which one $10 \mu \mathrm{g}$ meropenem disc has been previously placed aseptically and then incubated in ambient air overnight at $37{ }^{\circ} \mathrm{C}$. The overnight culture was then sub-cultured onto MacConkey agar plate and incubated again. All the bacterial isolates were identified using standard laboratory techniques (Cowan and Steel, 1993).

The CDC broth enrichment method employed in this study utilizes materials that are readily available even in resource constrained settings, which makes it easy to implement and most suitable for laboratories where molecular detection techniques and other highly sensitive phenotypic methods may be unavailable (AguirreQuiñonero and Martinez-Martinez, 2017; Richter and Marchaim, 2017).

\section{Isolation of Carbapenem Resistant Bacteria and Antimicrobial Susceptibility Testing}

All the isolates collected from the laboratory during the study period were phenotypically screened for carbapenem resistance using the disc diffusion method as described by Clinical and Laboratory Standards Institute (CLSI) guidelines (CLSI, 2016). Two standard carbapenem (imipenem $(10 \mu \mathrm{g})$ and meropenem $(10 \mu \mathrm{g}))$ discs sourced from Oxoid, UK, were used. The isolates with reduced susceptibility (total or intermediate) to carbapenem were regarded as carbapenem resistant. The carbapenem resistant bacterial isolates were subjected to antimicrobial susceptibility testing using the modified Kirby Bauer disc diffusion method on Mueller-Hinton agar plates (Oxoid Limited, Basingstoke, UK) according to the CLSI guideline. The antimicrobial agents used in this study (Oxoid Limited, Basingstoke, UK) were levofloxacin (5 $\mu \mathrm{g})$, ciprofloxacin $(5 \mu \mathrm{g})$, gentamicin $(10 \mu \mathrm{g})$, ceftriaxone $(30 \mu \mathrm{g})$, amoxicillin-clavulanate $(20 / 10 \mu \mathrm{g})$, cefotaxime $(30 \mu \mathrm{g})$. The inhibition zone diameter was measured and interpreted according to CLSI interpretative criteria.

\section{Detection of MBL Production}

The CR-GNB isolates were subjected to confirmatory test for MBL-production by the combined discs method as previously described (Aguirre-Quiñonero et al., 2017). This was performed by using two imipenem discs $(10 \mu \mathrm{g})$, one containing $10 \mu \mathrm{l}$ of $0.1 \mathrm{M}$ anhydrous ethylene diamine tetra-acetic acid (EDTA). The discs were placed $25 \mathrm{~mm}$ apart on Mueller-Hinton agar plates inoculated with the standardized inoculum of the test organisms. An increased inhibition zone diameter of $7 \mathrm{~mm}$ with imipenem-EDTA disc compared to imipenem disc alone was considered as MBL-positive.

\section{Statistical Analysis}

The data were analysed using GraphPad Prism ${ }^{\circledR}$ 7.0 software (GraphPad Software Inc., USA). Demographic characteristics (gender and age) and clinical (sample sources and source of bacterial isolates) variables were analysed by univariate analysis. Associations among variables were determined using Pearson's chi-square. In all cases, significance was assessed at $\mathrm{p}<0.05$.

\section{RESULTS \\ Patient Characteristics}

The study involved a total of 110 bacteria isolated from 47 female and 63 male patients with mean age of $28.09 \pm 2.12$ (Range: 9 months-79 years). Majority of the bacteria $(58 ; 52.7 \%)$ were isolated from urine samples. Others were obtained from stool samples $(27 ; 24.6 \%)$ and wound swab (22; 20\%) (Table1).

\section{Occurrence of Carbapenem Resistant Bacteria in the Hospital}

Overall, 31(28.2\%) of the Gram-negative bacterial isolates were carbapenem resistant. Of these, $14(29.8 \%)$ and $17(27.0 \%)$ were isolated from female and male patients, respectively (Table $2)$. The CR-GNB isolates were predominantly isolated from patients aged 18-50 years (Table 2). A statistically significant association was observed between the gender $(p<0.001)$ and age $(p<0.048)$ of the patients. About $50 \%$ and $25.92 \%$ of bacteria isolated from wound and stool samples were carbapenem resistant The result of chisquare test showed no significant association between sample sources and the isolation of carbapenem resistant bacteria ( $p>0.05)$.

Furthermore, a total of 19 (33.93\%) CR-GNB 
were isolated from 56 samples collected from the bed linens and rectum of patients involved in this study. The samples from the rectum and bed linens yielded $10(34.5 \%)$ and $9(33.3 \%)$ CR-GNB, respectively.

The distribution of the CR-GNB isolated from the hospital is presented in figure 1. E. coli (18; $36 \%$ ) was the most prevalent CR-GNB isolated from the hospital. This was followed in decreasing order of prevalence by Klebsiella spp. $(11 ; 22 \%)$, Salmonella spp. $(6 ; 12 \%)$ and Pseudomonas aeruginosa $(6 ; 12 \%)$.

Table 1: Characteristics of Patients Involved in the Study

\begin{tabular}{lcc}
\hline Characteristics & Frequency & Percentage \\
\hline Gender & & \\
Female & 47 & 42.7 \\
Male & 63 & 57.3 \\
\hline Age categories & & \\
\hline 0-17 years & 38 & 29.5 \\
18-50 years & 55 & 42.6 \\
51 years and above & 17 & 13.2 \\
\hline Isolates sources & & \\
\hline High Vaginal swab & 2 & 1.8 \\
Sputum & 1 & 0.9 \\
Stool Sample & 27 & 24.6 \\
Urine Sample & 58 & 52.7 \\
Wound swab & 22 & 20.0 \\
\hline Total & 110 & 100 \\
\hline
\end{tabular}

Table 2: Occurrence of Carbapenem Resistant Bacteria in the Hospital.

\begin{tabular}{|c|c|c|c|c|}
\hline Sample Sources & No screened & $\begin{array}{c}\text { Frequency of carbapenem } \\
\text { resistant isolates }\end{array}$ & $\mathbf{X}^{2-}$ value & p-value \\
\hline Bed linens & 29 & $10(34.48 \%)$ & 0.693 & 0.628 \\
\hline Rectal swab & 27 & $9(31.03 \%)$ & & \\
\hline \multicolumn{5}{|l|}{ Isolates sources } \\
\hline HVS & 2 & $0(0 \%)$ & 7.373 & 0.117 \\
\hline Sputum & 1 & $0(0 \%)$ & & \\
\hline Stool sample & 27 & $7(25.92 \%)$ & & \\
\hline Urine sample & 58 & $13(22.41 \%)$ & & \\
\hline Wound swab & 22 & $11(50 \%)$ & & \\
\hline \multicolumn{5}{|l|}{ Gender } \\
\hline Female & 47 & $14(29.8 \%)$ & 35.294 & $<0.001$ \\
\hline Male & 63 & $17(27.0 \%)$ & & \\
\hline \multicolumn{5}{|l|}{ Age (years) } \\
\hline $0-17$ years & 38 & $9(23.7 \%)$ & 6.090 & 0.048 \\
\hline $18-50$ years & 55 & $13(23.6 \%)$ & & \\
\hline 51 years and above & 17 & $9(52.9 \%)$ & & \\
\hline Total & 110 & $31(28.20 \%)$ & & \\
\hline
\end{tabular}




\section{Antimicrobial Susceptibility Testing}

The bacterial isolates showed varying pattern of resistance to the various antibiotics as shown in figure 2. Of the $50 \mathrm{CR}-\mathrm{GNB}$ isolates, a high resistance rate to cephalosporins was observed. Specifically, $76.7 \%$ and $71.3 \%$, of the isolates were resistant to ceftriaxone and cefotaxime, respectively. In addition, the results of the fluoroquinolone testing showed that $42.6 \%$ and $62.8 \%$ isolates were, respectively, resistant to ciprofloxacin and levofloxacin, while approximately $38.8 \%$ of the isolates were resistant to gentamicin. Interestingly, the isolates were more susceptible to amoxiclav, exhibiting only about $45.7 \%$ resistance. The majority of the CRGNB isolates were multidrug $(13 ; 26 \%)$ and extensively $(19 ; 38 \%)$ drug resistant, as defined by (Magiorakos et al., 2012) (Figure 3).

\section{Prevalence of Metallo- $\beta$-Lactamase Enzymes} The phenotypic MBL-production test revealed a high prevalence $(19 / 50 ; 38.0 \%)$ of MBL- positive isolates in the hospital as shown in figure 4. MBLproduction was more prevalent among Klebsiella spp. $(7 / 19 ; 36.8 \%)$, followed by $P$. aeruginosa (3/19;15.8\%) and Proteus spp. (3/19;15.8\%).

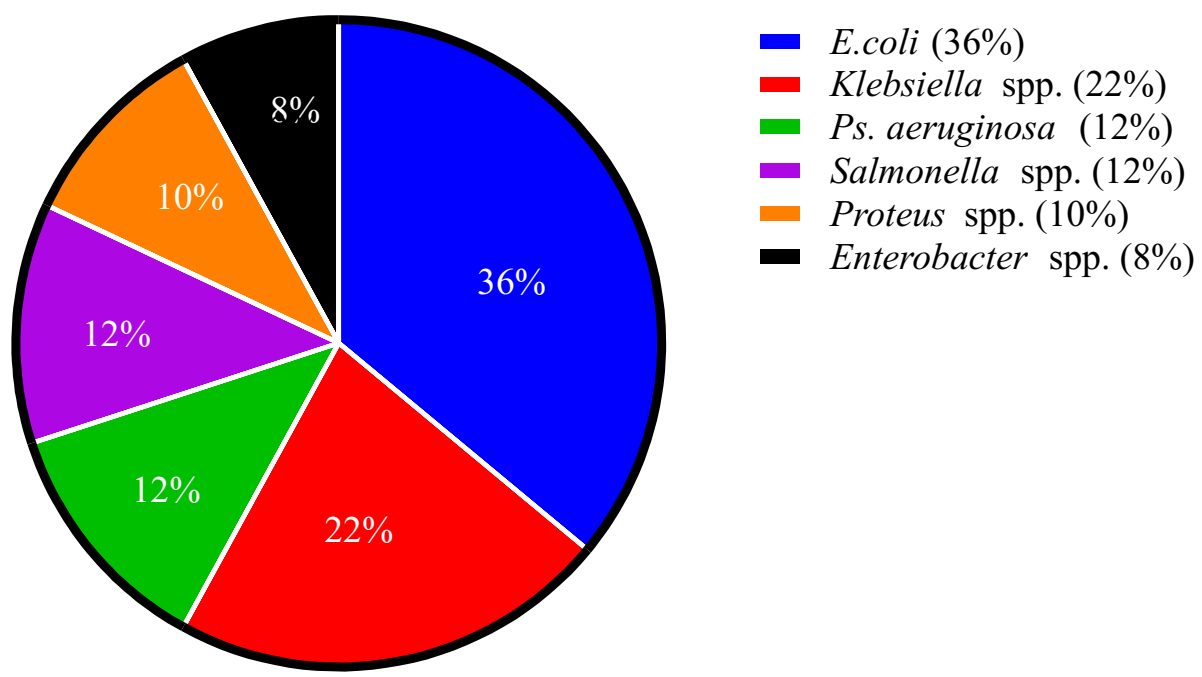

Figure 1: Frequency distribution of the isolated carbapenem resistant bacteria.

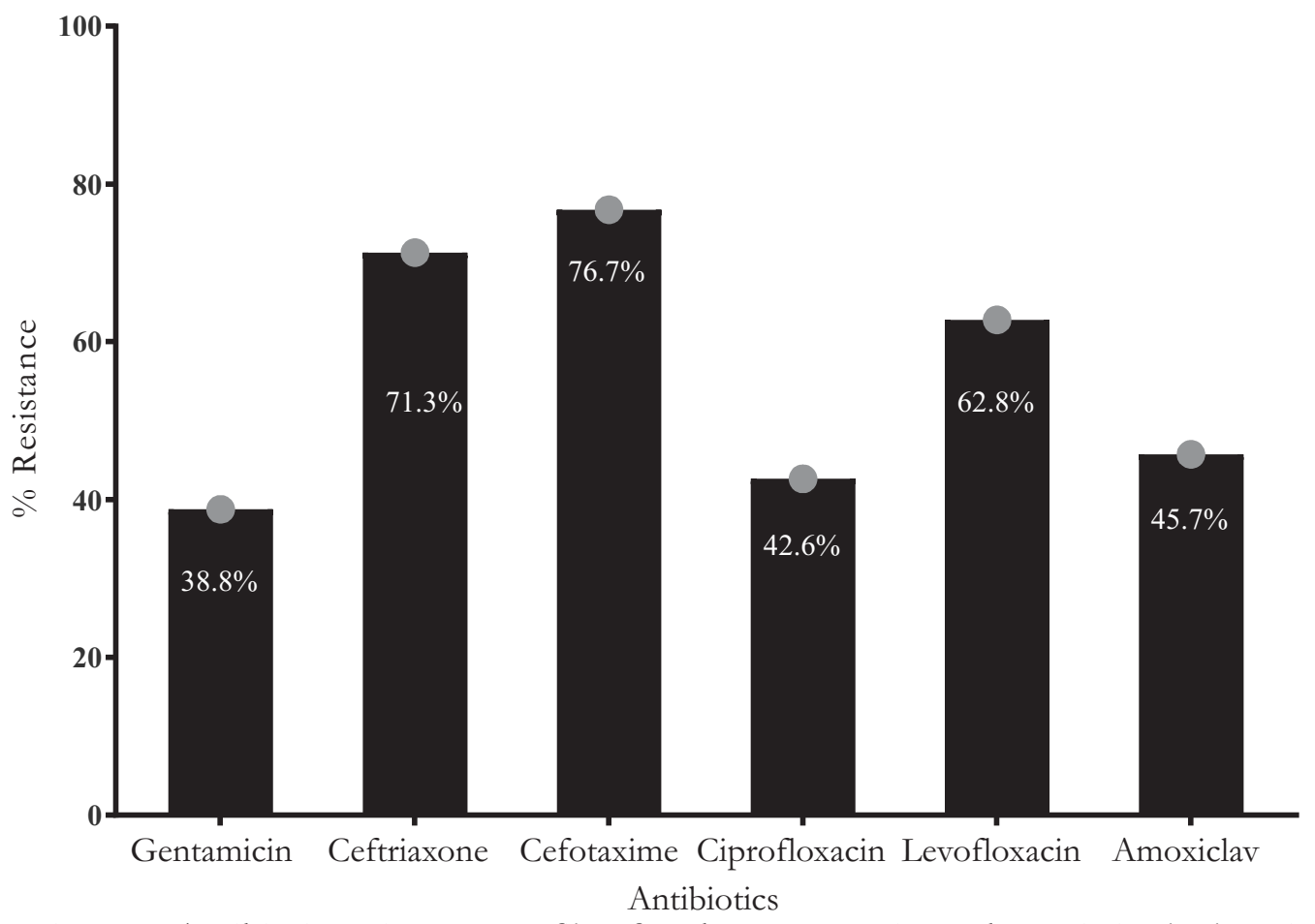

Figure 2: Antibiotic resistance profile of carbapenem resistant bacteria in the hospital. 


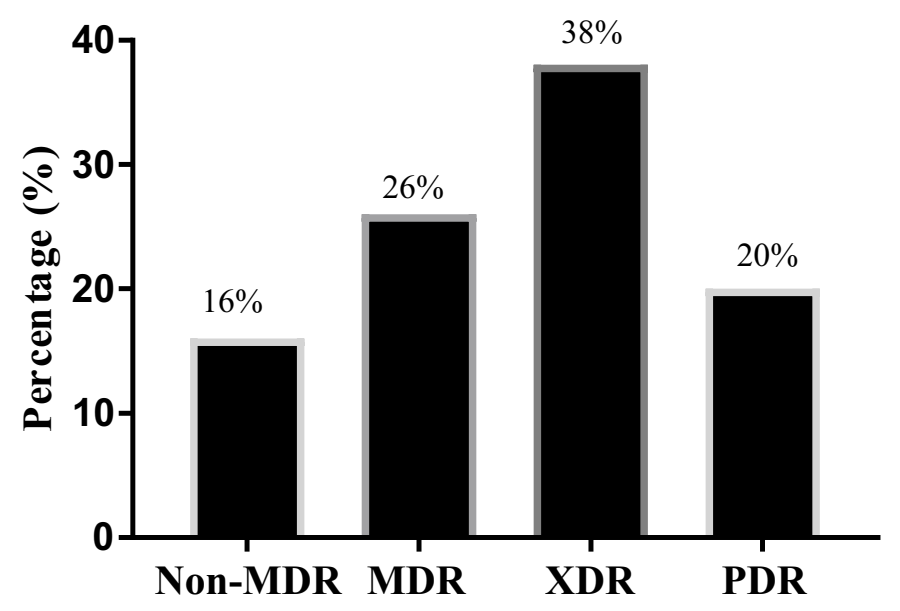

Figure 3: Distribution of MDR among carbapenem resistant isolates in the hospital.
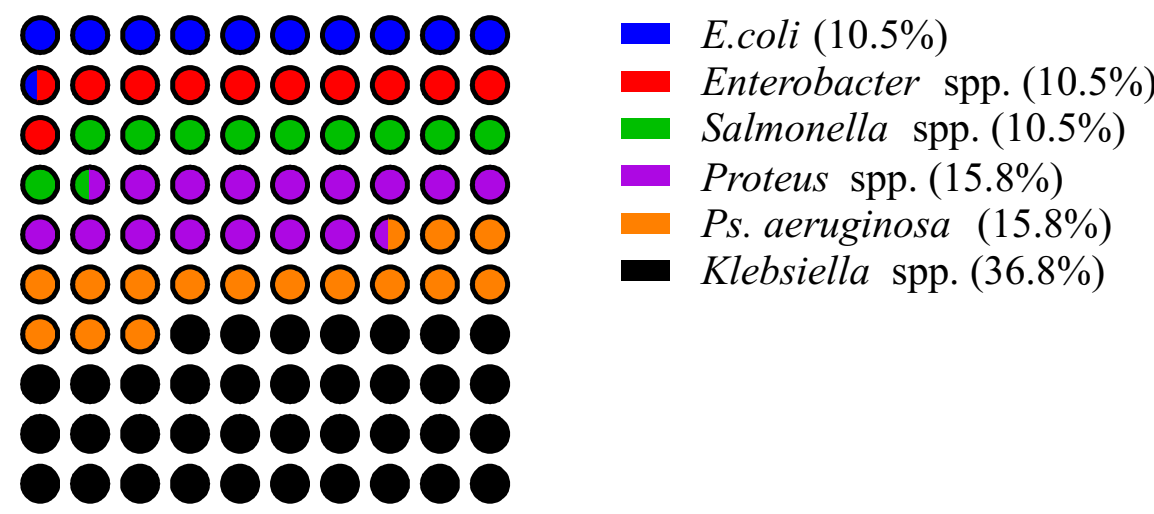

Figure 4: Prevalence of MBL-positive isolates in the hospital.

\section{DISCUSSION}

The carbapenem resistance in Gram-negative bacteria is increasingly encountered in healthcare and community associated infections. This has wide ranging implications on patient's management. The present study was conducted to investigate the occurrence of carbapenem resistant Gram negative bacterial (CR-GNB) isolates in a hospital with no history of carbapenem usage. The finding of $28.2 \%$ CRGNB among clinical isolates in this study contrasted with the higher $36.8 \%$ carbapenem resistance observed among clinical isolates collected from four tertiary hospitals in southwest Nigeria (Enwuru et al., 2011). It was however higher than $15.2 \%$ and $10.2 \%$ carbapenem resistance reported in Lagos and Maiduguri, southwest and northeast Nigeria, respectively (Oduyebo et al., 2015; Mohammed et al., 2015). The isolation of CR-GNB isolates from the bed linens of the hospital concur with a report that has shown extensive reservoir of carbapenem resistant organism in the hospital environment (Gordon et al., 2017). Similarly, the high faecal intestinal carriage of CR-GNB (31.03\%) observed in this study is alarming as this can serve as reservoirs for cross-transmission in health care settings (Viau et al., 2016).

Many factors may account for the isolation of CRGNB among patients with no history of previous exposure to carbapenem. Cross-resistance between carbapenem and other $\beta$-lactam antibiotics may result in independent emergence of CR-GNB. Beta-lactam antibiotics (cephalosporins and penicillins) are extensively used antibiotics in our hospitals, resistance to which has been well documented (Ibrahim et al., 2017; Olowo-okere et al., 2018). Furthermore, the observed CR-GNB might have been imported into this region by patients returning from other countries where CR-GNB is endemic. Reports of importation of antibiotic resistant bacteria across geographical border has been documented 
(Okeke and Edelman, 2001). Also, a recent systematic review has shown a high prevalent of antibiotic resistant bacteria at hajj which could be imported by pilgrimage to their respective countries on return (Leangapichart et al., 2017). In addition, the localisation of most carbapenemase genes on highly ambulatory genetic element may contribute to ease of acquisition and transmission of acquired carbapenem resistance among bacterial isolates in a hospital (Potter et al., 2016).

The high resistance of the isolates to other $\beta$ lactam antibiotics may be attributed to coproduction of both extended spectrum betalactamase (ESBL) and carbapenemase enzymes, resulting in hydrolysis of almost all $\beta$ lactam antibiotics. In Kano, Nigeria, isolates coproducing ESBL and MBL has been reported (Ibrahim et al., 2017). Despite the high resistance of the isolates to third generation cephalosporins and other $\beta$-lactam antibiotics, most of the isolates were susceptible to amoxiclav. This may also be due to the production of ESBL enzymes, as the hydrolytic activities of ESBL cannot be inhibited by $\beta$-lactamase inhibitors (Shaikh et al., 2015).

Our finding of $38.0 \% \mathrm{MBL}$-positive isolates in the hospital is contrasting with the lower $4.2 \%, 8.5 \%$ and $14.4 \%$ MBL-producing Gram-negative bacteria reported in Edo, Lagos and Kano, Nigeria, respectively (Oduyebo et al., 2015; Yusuf et al., 2015; Jesumirhewe et al., 2017) and higher than $73.1 \%$ reported in a multicentre study conducted in Kaduna and Kano, northwest, Nigeria (Yusuf et al., 2013). In sub-Saharan Africa, the prevalence of carbapenemase producing bacteria ranged from $9 \%$ to $60 \%$ (Manenzhe et al., 2015). The foregoing has shown that MBL-production is a major mechanism of acquired carbapenem resistant in most Nigerian hospitals.

This study involves only a single centre within the study area and so the findings cannot be generalized to the entire northwest region. Nevertheless, we believe the findings of this study are robust and exciting as it provides baseline data for the occurrence of CR-GNB in our environment.

\section{CONCLUSION}

This study revealed a high prevalence of metallo$\beta$-lactamase-producing carbapenem-resistant Gram-negative bacteria in a hospital with no history of its use. This report documents for the first time the independent emergence of such resistance in our hospital. Urgent implementation of adequate antibiotic stewardship program and other infection control measures is therefore imperative so as to contain this emerging threat.

Conflicts of Interest: We declare that we have no relevant conflict of interest.

\section{REFERENCES:}

Aguirre-Quiñonero, A., Cano, M. E., Gamal, D., Calvo, J., and Martínez-Martínez, L. (2017) Evaluation of the carbapenem inactivation method (CIM) for detecting carbapenemase activity in enterobacteria. Diagnostic Microbiology and Infectious Disease, 88(3): 214-218.

Aguirre-Quinonero, A., and Martínez-Martínez, L. (2017) Non-molecular detection of carbapenemases in Enterobacteriaceae clinical isolates. Journal of Infection and Chemotherapy, 23:1-11.

Aibinu, I., Nwanneka, T., and Odugbemi, T. (2007) Occurrence of ESBL and MBL in clinical isolates of Pseudomonas aeruginosa From Lagos, Nigeria. Journal of American Science, 3(4): 81-85.

CDC (2011) Laboratory protocol for detection of carbapenem-resistant or carbapenemaseproducing, Klebsiella spp. and E. coli from rectal swabs. www.cdc.gov / hai/setting. Accessed on 22/03/2018.

CDC (2013) Antibiotic resistance threats in the United States. Centres for Disease Control and Prevention, US Department of Health and Human Services, 2013.

CLSI (2016) M100S Performance standards for antimicrobial susceptibility testing. Clinical and Laboratory Standard Institute (M100Es26). Wayne, PA 19087 USA.

Cowan, T., and Steel, K. (1993) Cowan and Steel manual for the identification of medicallyimportant bacteria. Barrow, G. I. and Feltham, R. K. A. (Eds.) (3rd ed.). New York: Cambridge University Press. 
Dortet, L., Brechard, L., Poirel, L., and Nordmann, P. (2014) Rapid detection of c a r b a p e n e m a s e - p rod u c in g Enterobacteriaceae from blood cultures. Clinical Microbiology and Infection, 20: 340-344.

Duin, D. V., and Doi, Y. (2017) The global epidemiology of carbapenemaseproducing Enterobacteriaceae. Virulence, 8(4): 460-469.

El-gamal, M. I., Brahim, I., Hisham, N., Aladdin, R., Mohammed, H., and Bahaaeldin, A. (2017) Recent updates of carbapenem antibiotics. European Journal of Medicinal Chemistry, 131:185-195.

Enwuru, N. V., Enwuru, C. A., and Adepoju-bello, A. (2011) Metallo-beta-Lactamase production by Escherichia coli and Klebsiella species isolated from hospital and community subjects in Lagos, Nigeria. Nature and Science, 9:1-9.

Falagas, M. E., Tansarli, G. S., and Karageorgopoulos, D. E. (2014) Deaths attributable to carbapenem-resistant Enterobacteriaceae infections. Emerging Infectious Diseases, 20(7): 1170-1175.

Gordon, A. E. K., Mathers, A. J., Cheong, E. Y. L., Gottlieb, T., Kotay, S., Walker, A. S., Peto, T. E. A., Crook, D. W., and Stoesser, N. (2017) Is the hospital water environment a reservoir for carbapenem-resistant organisms causing hospital-acquired infections? A systematic review of the literature. Clinical Infectious Diseases, 64(10): 1435-1444.

Hsu, L.-Y., Apisarnthanarak, A., Khan, E., Suwantarat, N., Ghafur, A., and Tambyah, A. P. (2017) Carbapenem-resistant Acinetobacter baumannii and Enterobacteriaceae in South and Southeast Asia. Clinical Microbiology Reviews, 30(1): 1-22.

Ibrahim, Y., Sani, Y., Saleh, Q., and Saleh, A. (2017) Phenotypic detection of extended spectrum beta lactamase and carbapenemase co-producing clinical isolates from two tertiary hospitals in Kano , North West Nigeria. Ethiopian Journal of Health Science, 27(1):3-10.

Iovleva, A., and Doi, Y. (2017) Carbapenem- resistant Enterobacteriaceae. Clinical and Laboratory Medicine, 37(2): 303-315.

Jesumirhewe, C., Springer, B., Lepuschitz, S., Allerberger, F., and Ruppitsch, W. (2017) C a r b a p e n e m a s e - p r o d u c ing Enterobacteriaceae isolates from Edo State, Nigeria. Antimicrobial Agents and Chemotherapy, 18(8): 1-5.

Leangapichart, T., Rolain, J., Memish, Z. A., Altawfiq, J. A., and Gautret, P. (2017) Emergence of drug resistant bacteria at the Hajj: A systematic review. Travel Medicine and Infectious Disease, 18:3-17.

Logan, L. K., and Weinstein, R. A. (2017) The epidemiology of Carbapenem-resistant Enterobacteriaceae: The impact and evolution of a global menace. The Journal of Infectious Diseases, 215: 28-36.

Magiorakos, A. P., Burns, K., Baño, J. R., Borg, M., Daikos, G., Dumpis, U., Lucet, J. C., and Moro, M. L. (2017) Infection prevention and control measures and tools for the prevention of entry of carbapenemresistant Enterobacteriaceae into healthcare settings: guidance from the European Centre for Disease Prevention and Control. Antimicrobial Resistance and Infection Control, 6(113):1-17.

Magiorakos, A., Srinivasan, A., Carey, R., Carmeli, Y., Falagas, M., Giske, C. G., Harbarth, S., and Hindler, J. F. (2012) Multidrugresistant, extensively drug-resistant and pandrug-resistant bacteria: an an international expert proposal for interim standard definitions for acquired resistance. Clinical Microbiology and Infection, 18: 268-281.

Manenzhe, R. I., Zar, H. J., Nicol, M. P., and Kaba, M. (2015) The spread of carbapenemaseproducing bacteria in Africa : a systematic review. Journal of Antimicrobial Chemotherapy, 70:23-40.

Mohammed, Y., Zailani, S. B., and Onipede, A. O. (2015) Characterization of KPC , NDM and VIM type carbapenem resistance Enterobacteriaceae from North Eastern, Nigeria. Journal of Biosciences and Medicines, 3: 100-107. 
Olowo-okere et al.: Emergence of Metallo- $\beta$-lactamase Producing Gram-Negative Bacteria

Oduyebo, O., Falayi, O., Oshun, P., and Ettu, A. (2015) Phenotypic determination of c a rbapenemase producing Enterobacteriaceae isolates from clinical specimens at a tertiary hospital in Lagos, Nigeria. Nigerian Postgraduate Medical Journal, 22(4): 223-227.

Ogbolu, D., and Webber, M. (2014) High-level and novel mechanisms of carbapenem resistance in Gram- negative bacteria from tertiary hospitals in Nigeria. International Journal of Antimicrobial Agents, 43(5): 412-417.

Okeke, I. N., and Edelman, R. (2001) Dissemination of antibiotic-resistant bacteria across geographic borders. Clinical Infectious Diseases, 33: 364-369.

Olaitan, A. O. Morandj, S., and Rolain, J.M. (2016) Emergence of colistin-resistant bacteria in humans without colistin usage : a new worry and cause for vigilance. International Journal of Antimicrobial Agents, 47:1-3.

Olowo-okere, A., Ibrahim, Y. K. E., and Olayinka, B. O. (2018) Molecular characterisation of extended-spectrum â-lactamase-producing Gram-negative bacterial isolates from surgical wounds of patients at a hospital in North Central Nigeria. Journal of Global Antimicrobial Resistance, 14: 85-89.

Potter, R. F., Alaric, W. D., and Dantas, G. (2016) The rapid spread of carbapenem-resistant Enterobacteriaceae. Drug Resistance Updates, 29: 30-46.

Richter, S. S., and Marchaim, D. (2017) Screening for carbapenem-resistan t Enterobacteriaceae: Who, When, and How? Virulence, 8(4): 417-426.
Shaikh, S., Fatima, J., and Shakil, S. (2015) Antibiotic resistance and extended spectrum beta-lactamases: Types, epidemiology and treatment. Saudi Journal of Biological Sciences, 22(1): 90-101.

Viau, R., Frank, K. M., Jacobs, M. R., Wilson, B., Kaye, K., Donskey, C. J., Perez, F., Endimiani, A., and Bonomo, A. (2016) Intestinal carriage of carbapenemaseproducing organisms : Current status of surveillance methods. Clinical Microbiology Revieres, 29(1):1-27.

Walsh, T. R. (2005) The emergence and implications of metallo- $\hat{a}$-lactamases in Gram-negative bacteria. Clinical Microbiology and Infection, 11(6): 2-9.

Xu, L., Sun, X., and Ma, X. (2017) Systematic review and meta - analysis of mortality of patients infected with carbapenem resistant Klebsiella pneumoniae. Annals of Clinical Microbiology and Antimicrobials, 16(18):1-12.

Yusuf, I., Rabiu, A. ., Haruna, M., and Abdullahi, S. A. (2015) Carbapenem Resistant Enterobacteriacaea (CRE) in intensive care units and surgical wards of hospitals with no history of carbaprnem usage in Kano, North West Nigeria. Nigerian Journal of Microbiology, 27(1): 2612-2618.

Yusuf, I., Yusha'u, M., Sharif, A., Getso, M., Yahaya, H., Bala, J., IA, A., and Haruna, M. (2013) Detection of metallo betalactamases among Gram negative bacterial isolates from Murtala Muhammad Specialist Hospital, Kano. Bayero Journal of Pure and Applied Sciences, 5(2): 84-88. 